\title{
CURRÍCULO E EDUCAÇÃO INFANTIL: OS DESAFIOS PARA A GESTÃOO E PROFESSORES
}

DOI: $10.5902 / 2318133833722$

\author{
Márcia Pires Cardona \\ Colégio Riachuelo, Brasil.
}

Débora Teixeira de Melo

Universidade Federal de Santa Maria, Brasil.

\begin{abstract}
Resumo
Neste texto apresenta-se resultados de uma pesquisa que teve como objetivo compreender como os professores e gestores de três escolas municipais de educação infantil de Santa Maria/RS pensam acerca da proposta pedagógica a partir dos reflexos das diretrizes curriculares nacionais e da Base Nacional Comum Curricular. Para isso, buscou-se conhecer a realidade e o projeto pedagógico destas escolas, bem como aplicou-se um questionário pelo qual se indagou como ocorre a dinâmica de discussões e reflexões em cada uma sobre as políticas públicas, referenciais, diretrizes e currículo. Após o retorno dos questionários podemos fazer a análise das respostas com base em Bastos (2001), Cittolin (2014), Campos (1999), Dourado (2007), Kramer (2001), Kuhlmann (2001), Lück (2008), Zabalza (1998) e Rosemberg (1990). Vimos que esse tema ainda causa desconforto aos sujeitos por não sentirem-se parte dos processos e verem as políticas públicas como normas a serem seguidas.

Palavras-chave: políticas públicas; educação infantil; currículo.
\end{abstract}

\section{CURRICULUM AND CHILD EDUCATION: THE CHALLENGES FOR MANAGEMENT AND EDUCATORS}

\begin{abstract}
The present research has as main objective to understand how the educators and managers of three municipal schools of early childhood education of Santa Maria/RS are thinking the pedagogical proposal from the reflexes of the national curricular guidelines and the National Curricular Common Base. This topic was thought considering the guidelines for early childhood education and its implementation or not in the schools investigated. For this, we sought to know the reality of these schools initially, and the pedagogical project, in the second moment was applied the questionnaire where we asked how the dynamics of discussions and reflections in each one about public policies, referentials, guidelines and curriculum occurs. After the return of the questionnaires, we can make the analysis of the answers based on the theoretical contribution that guided the research such as Bastos (2001), Cittolin (2014), Campos (1999), Dourado (2007), Kramer , Lück (2008), Zabalza (1998) and Rosemberg (1990). We have seen that this subject still causes some discomfort to the subjects because they do not feel part of the processes, and see the public policies as norms to be followed directed to the teachers previously approved. We believe that this research portrays only the beginning of a discussion that needs to be taken up daily in the school environment so that a greater understanding of public policies can take place on the part of all those involved in the context of early childhood education.

Key-words: public policies; early childhood education; curriculum.
\end{abstract}




\section{Introdução}

partir das práticas profissionais vivenciadas no ambiente da educação infantil
e da possibilidade de integrar a equipe de tutores do curso de Pedagogia à
distância da Universidade Federal de Santa Maria, na disciplina de estágios supervisionados, surgiu a oportunidade de pensar a respeito das várias possibilidades lúdicas e criativas que envolvem a construção do conhecimento das crianças baseada nos estudos reflexivos propostos também pelo grupo de pesquisa Docência, infâncias e formação.

Uma das inquietações mais freqüentes se relaciona com as políticas públicas que regem o sistema educacional brasileiro, suas leis e normativas regulamentadoras. A principal indagação foi quais os reflexos que esses documentos têm na prática docente na educação infantil, ou qual a interpretação que assumem no cotidiano escolar? Assim, buscamos refletir sobre o caminho percorrido pelo sistema educacional no que se refere a educação infantil no Brasil, legitimada como primeira etapa da educação básica a partir da Lei de Diretrizes e Bases da Educação Nacional.

Em 1999, como forma de complementar essa normativa, foram elaboradas, pelo Conselho Nacional de Educação, as diretrizes curriculares nacionais da educação infantil, com revisão em 2009, pela resolução CNE/CEB n. 05/2009, com o objetivo principal de regulamentar e auxiliar a prática pedagógica desenvolvida pelos professores na infância.

Em 2013 iniciou-se a elaboração da Base Nacional Comum Curricular da Educação Básica, como forma de integralizar objetivos e metas a serem alcançados no que diz respeito às concepções, às aprendizagens e aos direitos particulares da infância.

Porém, ao pensarmos na educação infantil, precisamos refletir sobre qual a historicidade que envolve essas crianças, desde a criação das primeiras creches, a legitimação dentro do sistema de ensino até hoje? Que parâmetros curriculares são esses quando tratamos das crianças pequenas? E como tem se consolidado as propostas curriculares da educação infantil?

Dentro desta reflexão podemos dizer que a educação infantil passou por várias fases até se enquadrar no sistema como conhecemos hoje, com leis específicas que norteiam as políticas públicas relacionadas as crianças de zero a seis anos de idade. Entre essas fases pode-se citar que inicialmente o principal objetivo era o cuidado, ou seja, o caráter assistencialista visto principalmente nos lares e asilos administrados pela igreja, filantropia e caridade justificados pelos altos índices de mortalidade na época pelas precárias condições de vida. Neste contexto, surgiram as primeiras creches com objetivos mais amplos, que propõem algo além do cuidado. Esses primeiros ensaios aconteceram na França e logo se tornaram inspiração para outros países, entre eles o Brasil.

A partir da disseminação das creches e jardins de infância viu-se a necessidade de investigar esses sujeitos, suas características, demandas e necessidades, levando assim ao surgimento de várias pesquisas, estudos e normativas direcionadas exclusivamente para a educação infantil que nos guiam até agora.

Baseando-se nestas inquietações a pesquisa delimitou-se como qualitativa. Como instrumento de coleta de dados foi aplicado um questionário aberto com questões problematizadoras a respeito das experiências vivenciadas por gestores e professores no que tange a elaboração de uma proposta pedagógica a partir das diretrizes curriculares e da BNCC, como forma de basearem os relatos reflexivos destes sujeitos. 
A metodologia utilizada para a interpretação dos dados coletados no questionário foi a análise de conteúdo. Assim, os dados que foram observados serviram de base para a análise das impressões e experiências descritas pelos envolvidos de maneira reflexiva, buscando perceber o grau de relevância das propostas, seu entendimento e efetividade nas escolas de educação infantil investigadas.

\section{Educação infantil: histórico e legislação}

Em 1816, na Suíça, Robert Owen criou uma escola para atender os filhos dos funcionários da sua fábrica desde bebês até os 25 anos. Acreditava-se que se recebessem instruções claras e exatas sobre os objetos que a cercassem poderiam discernir entre as verdades gerais e as afirmações falsas. A partir daí várias outras iniciativas foram tomadas para tentar suprir a demanda observada na época, como em 1840, com a implantação dos primeiros jardins de infância na Alemanha, onde se buscou atender a crianças de 3 ou 4 anos de idade. Já as primeiras creches foram criadas mais tarde com o objetivo de atender àquelas entre 0 e 3 anos. Em parte isso ocorreu pela ideia de que os bebês necessitavam de cuidados específicos delegados as mães ou cuidadoras com conhecimentos sobre a saúde dos pequenos, devido os altos índices de mortalidade presentes na época decorridos da falta de infraestrutura das cidades, epidemias, precariedade na higiene e alimentação, por exemplo.

Foi a partir de 1870, na França, com os avanços na área médica a diminuição dos números de mortalidade que houve a possibilidade de ampliar a idade de atendimento das crianças na escola viabilizando-se o atendimento nas creches às crianças menores de três anos. Neste mesmo período, no Brasil, as investidas para a criação de instituições que atendessem a essas crianças começam a ser criadas.

No Rio de Janeiro, em 1875, foi fundado o primeiro jardim de infância privado do Brasil pelo médico Joaquim José de Menezes Vieira (1848-1897), sendo pioneiro no trabalho com as crianças pequenas. O Jardim das Crianças, vinculado ao Colégio Menezes Vieira, tinha como objetivo atender crianças da classe mais alta de sexo masculino entre 3 e 6 anos com atividades físicas, movimento, pintura, desenho, linguagem, cálculos, escrita, leitura, geografia, religião.

Para Bastos (2001), nesse período ficou evidenciado o caráter maternal dado à educação infantil visto o destaque dado ao trabalho ativo da esposa de Menezes Vieira na administração e organização do jardim das crianças:

Esta prática também insere-se na tendência da época de redimensionar o papel da mulher, na extensão de sua ação da esfera familiar (privada) para a esfera escolar (pública): o papel da figura feminina também o é de professora, entendida como extensão da ação materna: "a professora de um jardim de crianças faz, nada mais, nada menos, do que o papel de uma mãe zelosa do futuro de seu filho. (p. 33)

Para Rosemberg (1990), os estereótipos existentes frente à formação profissional das mulheres, retratado historicamente por estudos que remetem ao magistério como profissão de mulher, são vinculando em parte a questão da maternidade e consequente vocação feminina para a educação das crianças pequenas. 
A medida que as mulheres de classes sociais menos favorecidas começaram a ocupar cada vez mais espaços dentro dos pátios fábris viu-se aumentar a demanda por creches, visto que esses espaços eram destinados a crianças das classes sociais mais baixas:

\begin{abstract}
Embora as creches e pré-escolas para os pobres tenham ficado alocadas à parte dos órgãos educacionais, as suas inter-relações se impuseram, pela própria natureza das instituições. No estado de São Paulo, desde dezembro de 1920, a legislação previa a instalação de Escolas Maternais, com a finalidade de prestar cuidados aos filhos de operários, preferencialmente junto às fábricas que oferecessem local e alimento para as crianças. As poucas empresas que se propunham a atender os filhos de suas trabalhadoras o faziam desde o berçário, ocupando-se também da instalação de creches. (kulhmann, 2001, p. 8)
\end{abstract}

Com a Consolidação das Leis do Trabalho, aprovada em 1934, obrigou os estabelecimentos que possuíssem mais de trinta funcionárias a dispor de ambiente adequado para os filhos destas mulheres sob a vigilância e assistência no período de amamentação. Essa medida não foi cumprida na sua totalidade, visto que a maioria das mulheres operárias não eram beneficiadas pela existência das creches nas fábricas, muito menos a redução da carga horária para a amamentação. Somente mais tarde, com o ressurgimento dos movimentos feministas e mobilizações sindicais, houve um significativo aumento de berçários e creches destinados às mães trabalhadoras.

Essas iniciativas não podem ser consideradas como incentivadoras das políticas educacionais de implantação da educação infantil, visto que somente na década de 1970 ações significativas foram tomadas nesse sentido, ainda que de baixo custo e qualidade com a oferta de creches, jardins de infância, escolas maternais, parques infantis e préescolas.

Em reposta a necessidade, apontada em parte pelas manifestações organizadas pelos movimentos feministas e sociais, foram criadas medidas de amparo, não na esfera educacional, mas no âmbito da assistência social, dando conta de questões como o cuidado, a saúde e a nutrição, ainda restritas as classes mais baixas da população elevando o debate ao nível dos intelectuais da educação e comissões específicas.

A medida que as negociações e discussões sobre a votação da Constituição Federal de 1988 foram avançando, um novo movimento começou a se mobilizar a fim de garantir o direito das crianças e dos adolescentes, trazendo à tona as questões de violência que atingiam principalmente os jovens em situação de vulnerabilidade social.

Como reflexo da atuação de movimentos sociais e direitos humanos voltados para a juventude e infância, pela primeira vez as crianças de 0 a 6 anos foram vistas como partes integrantes do país munidas de direitos e por isso, resguardadas pela lei passando a ter a garantia de serem educadas em creches e pré-escolas merecedoras, portanto, da atenção legitimada pela Lei de Diretrizes e Bases da Educação.

Como forma de romper com esse paradigma, busca-se entender o processo educativo da criança pequena como um processo globalizado, em que possa se desenvolver de maneira integralizada todas as possibilidades do saber infantil, ou seja, a apropriação de hipóteses para a construção do próprio conhecimento, tendo como meios as artes, a cultura, o lazer, a saúde, a socialização, a afetividade. 
Assim, vemos que a escola para a criança representa um conjunto de possibilidades que devem estar disponíveis para serem exploradas constantemente. Não se trata apenas da construção de conhecimentos vinculados a conteúdos, ou programas escolares, mas da diversidade de saberes e relações que são desenvolvidas nos contextos da educação infantil.

Repensar a respeito das ações pedagógicas compreendendo a criança como protagonista do próprio desenvolvimento requer sensibilidade e comprometimento para proporcionar possibilidades necessárias à criação das hipóteses e descobertas que virão a seguir, seja pensando no mobiliário, nos materiais, na estrutura física, no fazer docente, nas propostas pedagógicas, na participação da comunidade escolar, enfim, nos vários aspectos que levam a compreensão da criança portadora de identidade e direitos.

A partir dos movimentos sociais nas décadas de 1970 e 1980, que levaram a reinvindicação das mulheres trabalhadoras pelo direito às creches, viu-se o início das discussões sobre a inclusão ou não das crianças pequenas no sistema educacional. As crianças de 0 a 6 anos passaram a serem vistas como partes integrantes do país munidas de direitos e por isso, resguardadas pela lei passando a ter a garantia de serem educadas em creches e pré-escolas.

Sobre a organização da educação nacional a LDB, no artigo 9ำ, inciso V, determinou que Estados, municípios e o Distrito Federal estabelecessem em colaboração, competências e normativas para a Educação Infantil, para nortearem os currículos e seus conteúdos mínimos, de modo a assegurar a formação básica comum. A obrigatoriedade surgiu também com forma de garantir o direito enquanto fator político fundamental na consolidação da educação infantil.

A legislação, a partir dos anos 1990, com o Estatuto da Criança e do Adolescente (1990), a Lei de Diretrizes e Bases da Educação (1996), seguidas nos pelos Planos Nacionais de Educação, PNE (2001-2010) e (2014-2024), tiveram como o objetivo garantir esse direito às crianças pequenas. Nesse momento de mudanças na legislação nacional, surgiu o Referencial Curricular Nacional para a Educação Infantil, lançado em 1998, considerado um parâmetro para nortear as propostas pedagógicas das instituições de Educação Infantil, levando em considerando as crianças como um ser social, histórico e cultural.

$\mathrm{Na}$ tentativa de dissipar divergências existentes sobre o texto do Referencial curricular nacional para a educação infantil (1998), o documento foi enviado a 700 profissionais em educação infantil, administradores e pesquisadores da área, que viram nessa iniciativa a responsabilidade de opinar sobre um dos mais importantes documentos norteadores das políticas públicas para a educação infantil no país.

Alguns pareceristas consideraram o documento relevante ou adequado, mas a grande maioria criticou o conteúdo sugerindo ampla revisão de todo o processo. Um dos principais pontos de debates foi a necessidade de investimento na formação qualificada para o professor da creche, além da necessidade de condições mínimas para a efetivação de um trabalho realmente educativo e pedagógico. Isso pressupõe um professor capaz de analisar metodologias, efetivar práticas e ainda estimular crianças e famílias criando condições de participação na comunidade escolar. 
Em 2008 a Coordenação Geral de Educação Infantil do MEC estabeleceu, com a Universidade Federal do Rio Grande do Sul, convênio de cooperação técnica para a articulação de um processo nacional de estudos e debates sobre o currículo da Educação Infantil. Disso resultou uma série de documentos, dentre eles Práticas cotidianas na educação infantil: bases para a reflexão sobre as orientações curriculares (MEC/Coedi, 2009).

Contudo, o marco importante na conquista da constituição desse espaço da educação infantil são as Diretrizes curriculares nacionais para a educação infantil, resolução de n. 05/2009. Essas diretrizes alinham as propostas de educação infantil orientando-as sobre as questões da diversidade cultural, religiosa, étnica e racial, bem como a concepção de educação infantil, de criança, de currículo, e de proposta pedagógica. Esse processo serviu de base para a elaboração de Subsídios para as diretrizes curriculares nacionais específicas da educação básica (MEC, 2009).

Em julho de 2009 foi designada a comissão que se encarregaria de elaborar novas diretrizes curriculares nacionais para a educação infantil. Em 5 de agosto de 2009, com a participação de representantes de entidades nacionais como União Nacional dos Dirigentes Municipais de Educação, Associação Nacional de Pós-Graduação e Pesquisa em Educação, Confederação Nacional dos Trabalhadores em Educação, Fórum Nacional de Conselhos Estaduais de Educação, Movimento Interfóruns de Educação Infantil do Brasil, bem como da Secretaria de Educação Básica da Secretaria de Educação Continuada, Alfabetização e Diversidade e das especialistas da área de Educação Infantil Maria Carmem Barbosa, Sonia Kramer, Fulvia Rosemberg, Ana Paula Soares Silva e Zilma de Moraes Ramos de Oliveira, o relator da Comissão, Raimundo Moacir Mendes Feitosa, apresentou um texto-síntese dos pontos básicos que seriam levados como indicações para o debate em audiências públicas nacionais.

Essas audiências foram promovidas pela Câmara de Educação Básica do CNE, em São Luís, Brasília e São Paulo. O processo de elaboração das diretrizes incorporou as contribuições apresentadas por grupos de pesquisa e pesquisadores, conselheiros tutelares, Ministério Público, sindicatos, secretários e conselheiros municipais de educação, entidades não governamentais e movimentos sociais que participaram das audiências e de debates e reuniões regionais. Como consequência destas iniciativas, esse processo educativo foi tornando-se alvo de estudos e pesquisas, surgiram aspectos, até então pouco explorados, como o caso do currículo desenvolvido nas escolas para as crianças pequenas.

Pesquisadores brasileiros iniciaram uma série de estudos e reflexões sobre o currículo motivadas pelas amplas discussões envolvendo a educação infantil. Essas iniciativas tiveram como objetivo analisar propostas e metodologias que auxiliassem secretárias na construção e implantação de suas próprias diretrizes curriculares. Esse processo foi feito em várias etapas: em primeiro lugar foi realizada a produção teórica sobre os principais contextos sobre propostas pedagógicas, curricular e projetos. Em seguida foram criados critérios para avaliação das propostas já existentes nos municípios. No terceiro momento foram formadas equipes do Ministério da Educação com consultores que visitaram creches e pré-escolas entrando em contato com os profissionais dessas instituições. 
Assim como em outros momentos em que houve a tentativa de estruturar qualquer tipo de proposta para a educação infantil. Entre essas discussões, algumas concepções importantes sobre o que é o currículo, superaram a dicotomia existente elevando o nível dos debates para um caráter mais pedagógico, menos pragmático e político. Kramer (2001) cita Kishimoto para tentar desenhar como a escola deve ser, precedendo ainda as definições de currículo propriamente ditas:

O currículo inclui definições sobre o tipo de escola que se deseja, o que se pretende oferecer, a forma de administrá-la, o contexto histórico, ideológico, filosófico, sociológico, cultural, político, econômico e psicológico em que se insere; trata das relações da escola e seu currículo com a sociedade como um todo, as metas, os conteúdos, os recursos, a avaliação, o desenvolvimento estratégias e modos de planejar e implementar o currículo, se orientado para a resolução de problemas, para o desenvolvimento infantil ou para experiências institucionais nacionais ou domésticas. (p. 7)

Essa concepção precisa estar bem clara para os agentes desta construção, pois precisam estar conscientes da importância da sua participação neste processo, visto a necessidade de identidade própria para cada proposta, qual a realidade em que a escola se encontra, quais as demandas sociais, quais os objetivos almejados, por exemplo. Talvez esses questionamentos possam levar a algumas respostas pertinentes e esclarecedoras no que tange a concepção curricular no cotidiano da Educação Infantil enquanto ambiente de desenvolvimento, socialização e construção de conhecimento infantil além de abrangerem os cuidados específicos de cada faixa etária.

Ao considerarmos a importância do currículo é preciso prever definições teóricas, metodológicas e práticas típicas do cotidiano escolar cabendo aos professores e gestores estabelecer quais as metodologias mais adequadas para cada realidade.

Desse modo, com a elaboração das diretrizes curriculares nacionais para educação infantil de 2009, o currículo foi visto e construído sob outros olhares que levam em conta o contexto interno e externo em que está a escola, bem como as relações que são construídas e mediadas pelas culturas existentes, pois ao se relacionar com seus pares, as crianças criam conhecimentos a partir das experiências que são compartilhas com o coletivo.

Muitas dessas experiências tornam-se possíveis se considerarmos a importância da organização do tempo, do espaço e dos materiais na educação infantil. Para isso, é importante que o professor tenha clareza da relevância que a organização do cotidiano escolar apresenta. Pensar à respeito do modo como as dinâmicas acontecem durante o período em que a criança está na escola revela o nível de atenção e cuidado que se têm para que esses momentos sejam significativos. É importante conhecer o grupo de crianças, como se relacionam, quais as brincadeiras preferidas e como elas se desenvolvem, qual o contexto sociocultural em que estão inseridas, as idades, em quais espaços gosta de brincar, o que lhes chama a atenção, etc.

Pela apuração, o professor poderá organizar o trabalho educativo tendo como foco as crianças, fazendo com que se envolvam na construção deste processo, que requer propostas dinâmicas, diversificadas e pensadas nas especificidades de cada grupo. Ou seja, o currículo precisa ser pensado a partir da escuta dos interesses das crianças, suas 
curiosidades e suas vivências. Outro aspecto importante que diz respeito a organização do tempo na escola é atenção dada à rotina, com seus horários definidos para sono, alimentação e higiene. Sobre isso é necessário problematizar como essas práticas cotidianas refletem na busca de experiências significativas na educação infantil por meio de iniciativas como adaptar o horário do sono a necessidade das crianças, diminuir o tempo em frente à TV, incentivar o desenvolvimento da autonomia das crianças, promover momentos de diálogo entre a família e a escola devendo estar presentes, também, os contextos sociais e familiares em que se inserem essas crianças, visto que essa articulação se faz necessária para que haja uma compatibilidade de valores e uma constante troca de experiências e descobertas. Nessa perspectiva, além da sala de aula, o currículo também precisa estar articulado às práticas culturais de determinado grupo social e suas particularidades.

Além dos RCNEls (1998) e das DCNEls (2009), outros documentos também foram produzidos pelo Ministério da Educação, como os Parâmetros nacionais para qualidade na educação infantil (2006), pelos quais se pretendia estabelecer padrões de referência orientadores para o sistema educacional no que diz respeito a organização e funcionamentos das instituições de Educação Infantil.

Dentro das várias iniciativas que foram observadas com o objetivo de regulamentar as práticas na educação infantil, enquanto primeira etapa da educação básica, houve a proposição da Base Nacional Comum Curricular - BNCC - como o empreendimento mais atual no que se refere a políticas destinadas a educação de crianças pequenas.

Pelo discurso da participação social foi formada uma equipe composta por professores universitários pesquisadores e demais representantes das organizações representativas nas questões da educação básica com a incumbência de organizar o documento que seria submetido a consulta popular. A partir do momento que esse documento foi disponibilizado promoveu-se a participação da sociedade e, após, o preenchimento de um cadastro, a possibilidade de enviar sugestões e opiniões para serem analisadas e assim auxiliar na reformulação do documento definitivo, além disso, vários encontros foram promovidos a fim de divulgar e mobilizar as secretarias de educação para a participação deste processo.

Após esse momento da consulta pública os resultados obtidos foram analisados por pesquisadores componentes do comitê para, a seguir, segundo o MEC, comporem a segunda versão do documento da base.

Inicialmente cercado de questionamentos, esse documento levou muitos professores a reverem seus próprios conceitos e práticas a fim de compreenderem quais os objetivos das políticas e quais suas implicações práticas no cotidiano da educação infantil. Entre as inquietações sentidas nas escolas, uma delas foi a questão das dimensões nacionais de abrangência da base, visto que por se tratar de uma política nacional, deixa de lado as peculiaridades regionais que caracterizam e influenciam as propostas pedagógicas de cada instituição.

Apesar de o texto propor uma dinâmica que valorize as concepções sobre a educação infantil, suas especificidades e demandas, o que se vê são preocupações que se justificam a medida que entendemos a base como documento norteador de nivelamento delimitado por conteúdos pré-estabelecidos através de objetivos de aprendizagens que envolvem experiências a serem vividas na infância. 
Após o período de análise desta segunda versão o Ministério da Educação divulgou a terceira versão do documento (2017). Inicialmente a proposta desta nova versão seria a reorganização textual do documento, porém o que se viu foram alterações significativas de teor pedagógico, como a mudança do título Direitos e aprendizagem $e$ desenvolvimento para Competências gerais da Base Nacional Comum Curricular, por exemplo.

No que se refere às crianças pequenas, vimos na versão final esse tipo de substituições, que levam em alguns casos a maior valorização da leitura e da escrita, em detrimento às outras linguagens, mesmo com o discurso de preservar os campos de experiências, trazendo à tona a ideia da Educação Infantil como etapa preparatória para os Anos Iniciais do Ensino Fundamental como vimos neste trecho do Estudo comparativo divulgado pelo MEC (2017).

Percebe-se que esse tipo de alteração adquire outro sentido do que foi discutido e ponderado nos fóruns de discussão promovidos pelas instituições ligadas a educação. Essa mudança também ocorre no campo Traços, sons, cores e imagens, que passou a se chamar Traços, sons, cores e formas, trazendo experiências ligadas aos conhecimentos matemáticos.

Cabe ressaltar que a aquisição da leitura, escrita e conhecimentos matemáticos compõe índices avaliativos que sustentam um grande número de políticas de financiamento tanto nacionais como internacionais. Algumas avaliações aplicadas na Educação Básica consideram apenas língua portuguesa e matemática, como o caso da Provinha Brasil aplicada às crianças no início e no final do $2^{\circ}$ ano.

Isso trás reflexos diretos a educação infantil por iniciativas que visam a elevar tais índices apressando o processo de alfabetização, eliminando assim etapas importantes e diminuindo o tempo de exploração das demais linguagens como artes, movimento, música, natureza e sociedade em detrimento àquelas avaliadas. Frente esse cenário cercado de dúvidas e inquietações, a Associação Nacional de Pós-Graduação e Pesquisa em Educação divulgou um documento caracterizado pela crítica à terceira versão da Base Nacional Comum Curricular de 6 de abril de 2017.

Essa crítica inicia pelo fato de que ao contrário do que foi feito nas primeiras duas versões, a autoria foi atribuída a especialistas dispensando a participação dos demais membros da sociedade como professores e demais profissionais atuantes na Educação Infantil.

Outra ressalva diz respeito ao fato de que importantes pressupostos relacionados ao desenvolvimento infantil foram suprimidos do texto da terceira versão como, por exemplo, parágrafos que tratam do desenvolvimento e aprendizagem das crianças pequenas e às questões relacionadas à linguagem que estavam presentes na versão anterior.

Esse tipo de alteração pode ser entendida para além de simples alterações textuais como divulgado, para mudanças que marcam outros rumos para a educação infantil levando a padronização e uniformidade, padronizando ações próprias às testagens em larga escala e às expectativas do mercado voltado aos produtos educacionais como apostilas e livros didáticos, desconsiderando as diversidades existentes no sistema educacional brasileiro. 
Os campos de experiência também sofreram alterações significativas, como no caso do campo Escuta, fala, linguagem e pensamento que foi substituído por Oralidade e escrita, relegando maior importância a alfabetização do que as demais linguagens observadas na aprendizagem infantil, delegando a aquisição da escrita como sendo prioritária às demais linguagens. Desta forma há o risco de desconsiderar a identidade que se pretende atribuir a educação infantil por estudos e reflexões que priorizam as especificidades da infância.

Outro ponto que divergiu entre as versões anteriores e a atual é o fato de que o corpo da criança, previsto no campo Corpo, gestos e movimentos ser percebido por um viés físico-motor e que precisa ser educado pela higiene e exercícios dos movimentos, desconsiderando o caráter simbólico como as problematizações de gênero e relações étnico-raciais que ficaram delegadas a segundo plano no texto atual.

Podemos perceber que a falta de coerência entre as versões que foram apresentadas podem servir de justificativa para a insegurança observada nas escolas quando o assunto é a Base Nacional Comum Curricular. Não se sabe ao certo quais serão os rumos que a educação infantil irá tomar a partir destas novas políticas, porém o momento exige diálogo e reflexões sobre o quais são os objetivos da educação infantil e como as escolas irão se adaptar a tais mudanças.

Conforme foi referido anteriormente essa proposta de pesquisa tem como sujeitos professores e gestores de três Escolas Municipais de Educação Infantil de Santa Maria/RS, sendo que duas ficam situadas na zona leste da cidade e uma na zona norte.

Segundo o projeto político-pedagógico da escola $A$, que tem sua versão mais atual datada de 2015, o principal objetivo é proporcionar condições adequadas para promover o bem estar da criança, seu desenvolvimento físico, motor, emocional, intelectual, moral e social, ampliando suas experiências, desenvolvendo o senso crítico, criatividade, participação, responsabilidade, sociabilidade e autoestima.

A segunda escola, $B$, localiza-se numa região mais central na zona norte de Santa Maria e busca, segundo o projeto político-pedagógico, desenvolver um trabalho comprometido com o atendimento às necessidades da comunidade de tal forma a atender também as crianças com necessidades especiais, buscando proporcionar a inclusão que Ihes é garantida por direito. Porém, a rede municipal não oferece profissionais da área para atuação dentro da Emei, mantendo apenas um sistema de apoio às dificuldades mais emergenciais.

A terceira escola observada, $C$, também se localiza na zona leste da cidade, em bairro diferente da escola $A$, e no seu projeto político-pedagógico vemos descritos além das características estruturais da escola, os objetivos, a metodologia, a rotina e a avaliação. Em sua proposta, direcionada aos professores, educandos e comunidade, mencionam a preocupação em atender de maneira global e comprometida com a formação do cidadão crítico, resgatando os valores, desenvolvendo as competências e habilidades de forma lúdica e criativa. Sobre o PPP vemos no texto da Proposta preliminar da base nacional comum curricular divulgado pelo Ministério de Educação (MEC/2016). 
Um aspecto que as três escolas têm em comum é o fato de que as gestoras estão no cargo de direção a bastante tempo, no caso da escola $\mathrm{B}$, por exemplo à dezesseis anos. Nos textos dos três PPPs vemos referências à respeito da gestão democrática e da importância da participação de todos membros da comunidade escolar nas decisões que envolvem a escola.

A partir dos questionários realizados, com questões abertas para problematizar e trazer à tona a opinião dos gestores e professores das três escolas de Educação Infantil sujeitos desta pesquisa buscamos analisar as concepções dos gestores e professores sobre as políticas vigentes.

Inicialmente foi feito contato com a direção das escolas à fim de apresentar a proposta e verificar a disponibilidade dos sujeitos para a participação na investigação sobre os novos parâmetros curriculares para a educação infantil. Neste primeiro momento as três escolas demonstraram interesse no tema e concordaram em participar. Duas delas, $\mathrm{B}$ e $\mathrm{C}$, inclusive disponibilizaram prontamente o projeto político-pedagógico e responderam alguns questionamentos informais sobre a realidade da escola e do público que atende. Porém, na escola $A$ percebeu-se uma resistência em possibilitar a consulta ao PPP, visto que foram necessárias várias visitas para que isso fosse possível.

$\mathrm{Um}$ aspecto que foi bastante significativo foi o fato de que foram disponibilizados cinco questionários em cada uma das escolas, totalizando quinze questionários, destes apenas sete foram respondidos. Sendo que a escola A mesmo estando ciente do teor das questões e do anonimato dos participantes não respondeu nenhuma das indagações feitas.

Assim, podemos ver que muitos profissionais da educação infantil não se percebem protagonistas dos processos que se desenvolvem a partir das políticas educacionais e que são refletidas diretamente no cotidiano escolar, preferindo muitas vezes privar-se de responsabilidade no posicionamento ou na tomada de decisões que interfiram no pragmatismo já existente. Porém, pela participação das outras escolas podemos perceber que a falta de disposição em participar da pesquisa reflete um posicionamento não pode ser considerado unanimidade entre os professores.

As indagações feitas pelo questionário tinham como principal objetivo buscar entender como os gestores e professores compreendem e interagem com as políticas educacionais vigentes, como as diretrizes curriculares nacionais (2009) e a Base Nacional Comum Curricular (2017), por exemplo.

Para chegarmos a esse entendimento, algumas questões foram pensadas visando à esfera micro organizacional das escolas, ou seja, sobre particularidades de cada um dos três contextos analisados, como: o projeto político-pedagógico, as reuniões pedagógicas e o planejamento.

Em relação à concepção de infância que caracteriza a proposta pedagógica da escola, uma das professoras da escola $\mathrm{B}$, diz que "nossa escola compreende a infância como um tempo único, de respeito à construção dos saberes. Nossa filosofia é "vendo a infância com os olhos da criança".

Essa concepção remete ao empenho em entender como acontece o desenvolvimento infantil a partir da inserção da criança na Emei, fazendo dela protagonista do próprio saber. 
Quando vemos essas políticas sendo postas em prática com o único objetivo de se cumprir normas e determinações legais, estamos esquecendo a complexidade que envolve a educação infantil. No texto da primeira versão da BNCC (2015) podemos ver como essa perspectiva é entendida:

As crianças vão se constituindo como alguém com um modo próprio de agir, de sentir e de pensar na interação com outras crianças e adultos. Conforme vivem suas primeiras experiências na coletividade, elaboram perguntas sobre si e os demais, aprendendo a se perceberem e a se colocarem no ponto de vista do outro, a se oporem ou concordarem com seus pares, entendendo os sentimentos, os motivos, as ideias e o cotidiano dos demais parceiros. Conhecer outros grupos sociais, outros modos de vida, por meio de narrativas, de contatos com outras culturas, amplia o modo de perceber o outro e desfaz estereótipos e preconceitos. (Brasil, 2015, p. 22)

Nesse sentido vimos que todas as respostas fazem menção ao trabalho pautado na ludicidade, no brincar e na importância da autonomia e socialização da criança.

Após a investigação sobre essas concepções, buscamos questionar como aconteceu a construção das propostas pedagógicas, e todas foram unânimes em citar a participação conjunta dos professores, equipe diretiva, pais e funcionários na construção do PPP. Uma das professoras refere-se ainda sobre as revisões que são feitas: "Foi construída com a participação dos professores. A proposta passa por reformulações periódicas e atualizada com a contribuição da equipe da escola" (professora da escola B).

Sobre esse processo de participação vimos que outro aspecto importante é a realização das reuniões pedagógicas. $\mathrm{Na}$ escola $\mathrm{B}$ as reuniões ocorrem semanalmente e constituem um momento para a reflexão dos referencias bem como para o planejamento. Já na escola $C$ esses encontros são mensais e os professores ainda não tem hora planejamento.

Nos dois casos analisados as reuniões pedagógicas são, segundo as respostas, momentos que propiciam discussões sobre os referenciais curriculares, constituindo também uma oportunidade de reflexão sobre o fazer docente.

Uma das indagações feitas buscou captar como a escola discute e/ou tem implementado as diretrizes curriculares, e mesmo com todas as demandas que surgem nas reuniões pedagógicas, os professores ainda aproveitam esse tempo para debater e se informar sobre as políticas. Na escola B, por exemplo, uma das professoras diz que "nas discussões que surgem durante os encontros de estudo, procuramos retomar as diretrizes e fazer um paralelo com a prática."

Em relação a BNCC, demonstrando inclusive a preocupação na participação do processo que culminou com a construção do documento definitivo apresentado em 2017, houve relatos tais como: "Sim, tivemos vários encontros em que discutimos a base, desde o princípio das discussões nacionais. Sempre acompanhamos o movimento" e "Sim, inclusive de forma bastante crítica e construtiva para o nosso trabalho."

Quando questionados sobre a importância dessas políticas, percebe-se que estes são considerados um aporte para fundamentar as práticas escolares, como nessa resposta da gestora da escola $\mathrm{C}$, "porque os mesmos oportunizam que os professores 
realizem seu planejamento considerando atividades adequadas às crianças, considerando espaços, materiais, tempos. Explorem brincadeiras e interajam construindo assim conhecimentos e novas aprendizagens." $\mathrm{Na}$ escola B, "os referenciais possibilitam estruturar e organizar uma linha de trabalho, que considere a criança como sujeito e protagonista da vida na escola. Eles contribuem com o planejamento, mas sempre considerando o contexto de cada criança."

Deste modo percebemos que além de desempenhar o papel legitimador, ao definir as condutas para a educação infantil, os referenciais atuam como um norte para as metodologias e ações vivenciadas no cotidiano escolar sendo usado para conduzir as práticas docentes.

\section{Considerações finais}

Durante as reflexões feitas nesta pesquisa sobre as Diretrizes curriculares nacionais (2009), Base Nacional Comum Curricular (2017), pensadas a partir da ótica dos professores e gestores na educação infantil buscamos analisar como as políticas públicas tem sido tratadas no contexto das Emeis investigadas, pertencentes a rede pública de ensino de Santa Maria/RS.

Como objetivo principal, buscamos compreender como os professores e gestores destas três escolas municipais de educação infantil estão pensando a proposta pedagógica a partir dos reflexos das diretrizes curriculares nacionais e da Base Nacional Comum Curricular.

Como toda pesquisa que busca desenvolver-se sob um debate reflexivo permeado de significado, esse estudo trouxe uma série de inquietações trazidas inicialmente pela própria pesquisadora enquanto acadêmica do curso de Especialização em Gestão Educacional e docente da educação infantil. Depois de vários anos de atuação no cotidiano infantil, suas práticas e metodologias, próprias da sala de aula, voltar às atenções para as questões teóricas e burocráticas que envolvem as políticas públicas na educação infantil, foi certamente um desafio motivado pela ânsia em compreender os nortes que a educação infantil está seguindo.

Paulatinamente, conforme as leituras que deram o aporte teórico a esta pesquisa foram avançando, percebemos que não existe separação entre a teoria estudada, a prática vivenciada em sala de aula, e as leis que legitimam o sistema educacional. Isso foi constatado também durante analise dos questionários disponibilizados aos professores e gestores das escolas, deixando claro que além de ser uma inquietação pessoal é também de outros professores.

Imergir no contexto das políticas públicas requer o desprendimento de paradigmas que poderão calcificar o trabalho docente na maioria das vezes. Não desenvolvemos aquilo que não conhecemos e assim, deixamos de lado parâmetros, referenciais, diretrizes, pesquisas, aspectos que tratam da legitimidade educacional e que conferem critérios, objetivos e qualidade ao sistema, tornando o trabalho docente limitado ao seu contexto de sala de aula. 
Ao ir às escolas na busca por respostas, vimos gestores desconfortáveis com a possibilidade de não terem respostas certas para as perguntas ou não saber quais as melhores respostas. Esse aspecto demonstrou o quão inseguros alguns professores sentem-se em relação a políticas públicas preferindo abstecer-se de participar da pesquisa.

Porém, percebemos que a efetivação ou não das leis depende do tempo e do espaço que os professores têm para conhecerem o teor das normativas que norteiam o trabalho com as crianças. Desta forma, para eles, as reuniões pedagógicas constituem-se num espaço de estudo e consequentemente de formação docente como foi demonstrado através das respostas no questionário.

Algumas dessas respostas levam a entender que os textos provenientes dos documentos como referenciais, diretrizes e a base, servem de aporte teórico para a construção dos planejamentos como, por exemplo, "acredito que reflexão sobre a prática, o conhecimento e estudo periódico sobre as diretrizes ajudam o professor a planejar baseado nas diretrizes curriculares" (professora da escola B).

Outro aspecto que ficou evidenciado é a questão de que alguns professores consideram as políticas vigentes como algo distante da realidade que vivem sendo feitas para um público pré-determinado não condizendo com a realidade que muitas escolas se encontram. Essa visão demonstra uma inquietação presente de que as normativas legais foram criadas para serem cumpridas, sem a efetiva participação dos professores, gestores, ou mesmo dos demais membros da comunidade escolar.

Atualmente percebemos o movimento gerado pela construção da base nacional comum curricular que utilizou da mídia para propagar a importância de todos neste processo, porém durante a análise do questionário, percebemos que entre as três escolas, apenas uma mencionou a sua participação através do acompanhamento das notícias, reportagens, debates e estudos sobre a base. Mesmo tendo sido divulgada a ampla participação dos professores, sabemos que muitos preferiram esperar os rumos que esse documento teria, até pela falta de acesso digital aos formulários de participação, para discutir na esfera da escola como efetivar as novas propostas trazidas.

Podemos pensar que parte disto ocorre pela falta de momentos dedicados exclusivamente à formação continuada, visto que, conforme foi respondido durante a pesquisa as reuniões pedagógicas são momentos que precisam dar contas das discussões políticas, metodológicas, teóricas, sobre os problemas cotidianos, financeiros, estruturais, burocráticos, num tempo restrito para tantas demandas.

Os momentos de diálogo são insuficientes para promover discussões significativas sobre os rumos que a educação infantil está tomando e caráter nacional de forma reflexiva e crítica, que torne possível uma intervenção nas políticas em âmbito nacional, principalmente se pensarmos que muitos destes sujeitos estão há bastante tempo longe dos cursos de formação como graduação ou pós-graduação, por exemplo, e que essa formação inicial ocorreu em um tempo histórico diferente, com demandas sociais diferentes, sujeitos diferentes, para uma escola diferente.

Estar em contato com essas inquietações foi fundamental para perceber que na maioria das vezes as politicas públicas pensadas para a educação infantil ainda estão longe da compreensão dos professores, por falta de identificação destes com as iniciativas organizadas pelos órgãos legitimadores do sistema educacional brasileiro. 
Ainda há espaço para discussões, debates, reflexões, pesquisas para que as políticas públicas tenham o alcance esperado no que diz respeito a garantia de uma educação de qualidade que respeite as especificidades da infância, que respeito os direitos das crianças e que tenha nos seus sujeitos o centro das suas ações.

\section{Referências}

ANPED. Contribuições do GT07 à elaboração de posicionamento da Anped sobre a terceira versão da proposta de Base Nacional Base Nacional Comum Curricular (BNCC) encaminhada ao Conselho Nacional de Educação (CNE). São Paulo: Anped, 2017.

BALL, Stephen J; MAINARDES, Jefferson (org.). Políticas educacionais: questões e dilemas. São Paulo: Cortez, 2011.

BASTOS, Maria Helena Camara. Jardim de crianças: o pioneirismo do Dr. Menezes Vieira (1875-1887). In. MONARCHA, Carlos (org.). Educação da Infância brasileira (1975-1983). Campinas: Autores Associados. 2001, p. 31-79.

BRASIL. Base comum curricular: proposta preliminar, 2ª versão. Brasília: MEC, 2016.

BRASIL. Base nacional comum curricular: estudo comparativo entre a versão 2 e a versão final. Brasília: Coordenação de Edições Técnicas, 2017.

BRASIL. Constituição da República Federativa do Brasil. Brasília: Senado Federal, 2016.

BRASIL. Lei de Diretrizes e Bases da Educação. Brasília: Senado Federal, 2005.

BRASIL. Base nacional comum curricular - versão preliminar. Brasília, 2015. Disponível em <http://basenacionalcomum.mec.gov.br/\#/site/conheca>. Acesso em: 20 de agosto 2017.

BRASIL. Diretrizes curriculares nacionais para a educação infantil. Resolução n. 5 de 17 de dezembro de 2009. Brasília: MEC/SEB, 2010.

BRASIL. Referencial curricular nacional para a educação infantil. Brasília: MEC/SEF, 1998.

BRASIL. Indicadores da qualidade na educação infantil /. Brasília: MEC/SEB, 2009.

BRASIL. Parâmetros nacionais de qualidade para a educação infantil. Brasília: MEC, 2006.

CAMPOS. Maria Malta: A mulher, a crianças e os seus direitos. Cadernos de Pesquisa, n. 106, 199, p. 117-127.

FORTUNATTI, Aldo. A abordagem de San Miniato para a educação das crianças: protagonismo das crianças, participação das famílias e responsabilidade da comunidade por um currículo possível. San Miniato: ETS, 2014.

GOMES, Romeu. Análise e interpretação de dados de pesquisa qualitativa. In. DESLANDES, Suely Ferreira. GOMES. MINAYO, Cecília de Souza (org.). Pesquisa social: teoria, método e criatividade. Petrópolis: Vozes. 2009, p.67-80.

KRAMER, Sonia. Propostas pedagógicas ou curriculares de educação infantil. 24 REUNIÃO DA ANPED, 24, 2001. Anais ... Rio de Janeiro: PUCRIO, 2001.

KRAMER, Sonia; NUNES, Maria Fernanda. Gestão pública, formação e identidade de profissionais de educação infantil. Cadernos de Pesquisa, v. 37, n. 131, 2007, p. 423-454. 
KUHLMANN, Moysés Jr. O Jardim de infância e a educação das crianças pobres: final do século XIX, início do século XX. In: MONARCHA, Carlos (org.). Educação da infância brasileira (1875-1983). Campinas: Autores Associados. 2001, p. 3-30.

KUHLMANN JR, Moysés. Concepções e processos democráticos de gestão educacional. Petrópolis: Vozes, 2006.

MELLO, Débora Teixeira de; CORREA, Aruna Noal. Docências na educação infantil: reflexões sobre os ciclos de formação no projeto Proinfância. In: MELLO, Débora T de. CORREA, Aruna N; CANCIAN, Viviane Ache (orgs.). Docências na educação infantil: currículo, espaços e tempos. Santa Maria: UFSM, 2016, p. 41-67.

ROSEMBERG, Fúlvia. Mulher e educação formal no Brasil: estudo da arte e bibliografia. Brasília: FCC, 1990.

ZABALZA, Miguel A. Qualidade em educação infantil. Porto Alegre: Artmed. 1998.

Márcia Pires Cardona é licenciada em Pedagogia, especialista em Gestão Educacional pela Universidade Federal de Santa Maria e atua como professora da educação infantil no Colégio Riachuelo.

Endereço: Rua Liberato Salzano Vieira da Cunha, 605 - 97105-090 - Santa Maria RS - Brasil.

E-mail: mcardonix@gmail.com.

Débora Teixeira de Mello é professora no Departamento de Administração Escolar do Centro de Educação da Universidade Federal de Santa Maria.

Endereço: Rua Alameda Santiago do Chile, 205/201 - 97050-685 - Santa Maria - RS

- Brasil.

E-mail: deboramellors@yahoo.com.br.

Recebido em 17 de julho de 2018.

Aceito em 22 de agosto de 2018.

(c) (i) 